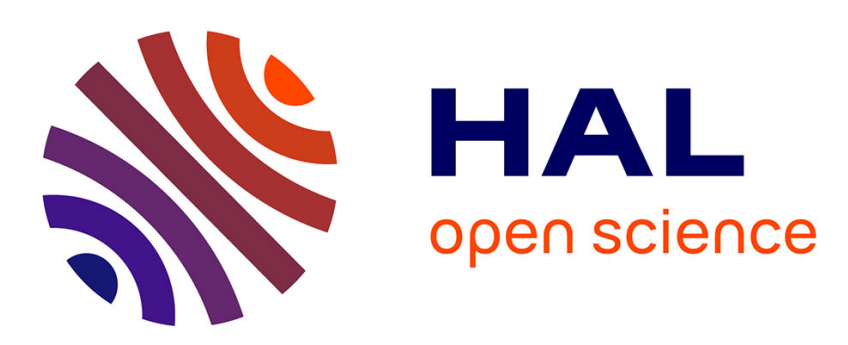

\title{
A fast compact model to simulate the heat exchanges in a bundle of electric wires
}

Julien Petitgirard, Philippe Baucour, Didier Chamagne, Eric Fouillien, Jean-Christophe Delmare

\section{- To cite this version:}

Julien Petitgirard, Philippe Baucour, Didier Chamagne, Eric Fouillien, Jean-Christophe Delmare. A fast compact model to simulate the heat exchanges in a bundle of electric wires. Thermal Science and Engineering Progress, 2020, 20, pp.100674. 10.1016/j.tsep.2020.100674 . hal-02993888

\section{HAL Id: hal-02993888 \\ https://hal.science/hal-02993888}

Submitted on 7 Nov 2020

HAL is a multi-disciplinary open access archive for the deposit and dissemination of scientific research documents, whether they are published or not. The documents may come from teaching and research institutions in France or abroad, or from public or private research centers.
L'archive ouverte pluridisciplinaire $\mathbf{H A L}$, est destinée au dépôt et à la diffusion de documents scientifiques de niveau recherche, publiés ou non, émanant des établissements d'enseignement et de recherche français ou étrangers, des laboratoires publics ou privés. 


\title{
A fast compact model to simulate the heat exchanges in a bundle of electric wires
}

\author{
Julien PETITGIRARD ${ }^{[1,2]}$, Philippe BAUCOUR ${ }^{[1 *]}$, Didier CHAMAGNE ${ }^{[1]}$, Eric FOUILLIEN ${ }^{[2]}$, \\ Jean-Christophe DELMARE ${ }^{[2]}$ \\ ${ }^{[1]}$ FEMTO-ST Institute, CNRS, Univ. Bourgogne Franche-Comte \\ ENERGIE Department, 2 av. Jean Moulin, 90000 Belfort, France \\ ${ }^{[2]}$ Groupe PSA, Technical Center of Velizy \\ 78140 Velizy-Villacoublay, France \\ ${ }^{[*]}$ philippe.baucour@univ-fcomte.fr
}

\begin{abstract}
The challenges of improving wiring harness designs in automotive, aerospace or transport fields are safety, ecology, weight, and cost. To this end, harnesses require superior thermal management, which involves considering several thermal sources with an uncontrolled layout. To date, the primary methods employed for thermal resolution are based on commercial softwares with meshing capabilities because evaluating temperature evolution influenced by several sources in an uncontrolled wire layout is difficult. This study presents a faster alternative method in which an equation based on the Infinite Line Source (ILS) model is used to create a nodal network. A more efficient matrix mathematical application is adapted to solve faster the ILS model. The ILS model relies on a fully connected node network. The wire bundle is a complex system with a variable environment and an uncontrolled wire layout. This work improves and adapts a fast mathematical model to complex geometries. Thus, the adaptation required by the model involves many assumptions. This new approach was tested on 2-wire and 10-wire layouts and then compared with results obtained by using a commercial software: ANSYS FLUENT. Some gaps exist between these methods. We propose a corrective model that uses equivalent conductivity to solve that issue.

Keywords: Infinite line source, Thermal nodal network, wiring harness, electric bundle, equivalent thermal conductivity, analytic resolution, automotive, aerospace, transport.
\end{abstract}

\section{Nomenclature}

\section{Abbreviation}

FEM Finite Element Method

FVM Finite Volume Method

ILS Infinite Line Source

\section{Greek Symbols}

$\Delta T \quad$ Temperature difference between wire and boundary

$\left[{ }^{\circ} \mathrm{C}\right.$ or $\left.\mathrm{K}\right]$

$\lambda \quad$ Thermal conductivity

$\left[\mathrm{W} \cdot \mathrm{m}^{-1} \cdot \mathrm{K}^{-1}\right]$ 
$\tau \quad$ Cooper area to bundle area ratio

$\zeta \quad$ Geometrical parameter of inclusions

\section{Roman Symbols}

$D \quad$ Distance between the centers of wires

I Electrical current

$N \quad$ Number of wires

$q \quad$ Heat source

$r \quad$ Radius

$R^{\Delta} \quad$ Thermal resistance used in network analyses

$R^{o} \quad$ Thermal resistance from analytical solution

$r p_{i, o} \quad$ Internal (i) or external (o) insulation radius

T Temperature

$x, y \quad$ Position

\section{Subscripts}

$\begin{array}{ll}\text { air } & \text { Domain of fluid } \\ b & \text { Boundary } \\ \text { cor } & \text { Core } \\ e q & \text { Equivalent value } \\ i, j & \text { Indices of matrix elements } \\ i n s & \text { Insulation } \\ m & \text { Studied wire indices } \\ n & \end{array}$

\section{Introduction}

\subsection{Context}

In recent years, there has been an increase in electricity consumption in automotive vehicles, which is in part due to automakers adopting a drive-by-wire approach, i.e., using electric wires to control regular operations

5 that involves electrifying mechanical or hydraulic systems $[1,2]$. For example, a mechanical direction detector is 
replaced with electronic sensors and an electrical power steering engine. Furthermore, enhanced functionalities, coupled with environmental and safety requirements, necessitate the use of more electrical appliances, and this has led to an increase in the number of wires in a vehicle. However, each wire needs to be properly designed as it warms up via the Joule effect and can thus be degraded. A good design allows for a mastered electric architecture and minimal weight, which facilitates better control of environmental impact, compliance to new ecological standards, and a slight breakaway from copper dependence.

In vehicles, the bundles are very complex and contain a lot of different wires. Over a kilometer of wires with a weight between 14 and 26 kilograms is distributed throughout the car. There are lot of different harnesses for any single vehicle model: differences in engines or options lead to a great variety of harnesses [3]. Furthermore, each electrical harness is made without a controlled layout of the wires in the bundle [4]. Moreover, the section size, type of insulation, type of sheath and thermal condition varies all along the harness. For example, a heated seat is powered with a current of around 5 amperes which runs in a wire with a cross-section of $4 \mathrm{~mm}^{2}$. Other power or communication wires with a cross-section between 0.3 and $10 \mathrm{~mm}^{2}$ are also present around it in the same bundle. The distribution of different ambient temperatures around the harness complicates the design. In vehicle, it is usual to find at least 3 critical ambient temperature ranges: from 100 to $110{ }^{\circ} \mathrm{C}$ under the hood, between 90 and $110^{\circ} \mathrm{C}$ in the dashboard and around $85^{\circ} \mathrm{C}$ close to the harness in the vehicle cockpit. To reduce the heating of the wires, designers can increase the section of the wires to lower its resistance and therefore its Joule effect. For areas where environments are restrictive, designers can also adapt the type of insulation that can withstand the temperature encountered. For example, a thermal class 3 insulation often made of PVC is adapted for a maximum wire temperature at $125^{\circ} \mathrm{C}$. A thermal class 4 can be made of PTFE for a maximum wire temperature of $150^{\circ} \mathrm{C}$.

\subsection{Subject}

Currently, there are many thermal studies on a single wires. Others studies are related to the thermal behavior in bundles. However, none of these studies allows to quickly model specific cases of thermal behavior for harnesses with a random layout. For example, the most simple assumption to thermally design harnesses is to study a single wire. In his study, Brito Filho [5] researched a one-dimensional steady-state conduction of heat in an infinitely long two-layer cylinder. It was established that the temperature depends on volumetric heat generation with specified surface temperature, specified convection, and radiation heat transfer. Outside the automotive domain, some other researchers have studied the model analytics of a buried electrical cable $[6,7,8]$.

35 For the automotive domain, Grandvuillemin $[9,10]$ developed a nodal method to design separately each wire of a bundle. His main assumptions were: one wire in a convective area, a transient problem, an axial and radial resolution. This study disregards the thermal effects between neighboring wires while facilitating the solving of different harness configurations.

In the automotive and aerospace fields, Chevrié [11], Benthem [12], Rickman [13], and Loos [14] studied models for one wire. They then extended their model to represent a bundle. Their representations are analytical but allow for a simple layout. Benthem [12] organizes each wire in concentric layers. Rickman [13] developed a solution where thermal conductance between each neighboring wire must be known. The difficulty to know these conductances requires a simple wire disposition. The bundle's model of Loos [14] has been validated to a ratio of the core surface, insulation, and air; it is independent of the wire disposition and does not allow the 
use of different materials for each wire. Mahiddini [15] used Methods of Moments to solve the electromagnetic compatibility (EMC) and the temperature field in a bundle. This method is neither adaptable nor efficient for harness diversity.

Multiple heat source systems also exist in other domains: the geothermal heat exchangers $[16,17,18,19$, $20,21]$, the winding heads of electric machines [22, 23] and other specific systems such as the heated pavement system to de-ice an airfield runway $[24,25]$. These multiple heat source issues can be solved using numerical methods like the Finite Element Methods. However, its implementation is specific for each case study. So, each case implies a new geometry and therefore a specific mesh. An analytical resolution could be a faster alternative method but only for simplified or adapted problems. In the literature, there is no analysis of a multi-source problem adapted to a bundle with a random wire layout.

Nian [26] enumerates several solutions using different semi-analytic methods. His propositions apply to a geothermal problem, while this study presents an adaptation of those propositions to a bundle. We use the infinite line source (ILS) model used in Hellström's research [18]. He proposed a nodal network method called the multipole method which is applied to study. Each geothermal energy pipe is a thermal source which is analogous to each wire in our case. Each source is studied individually, using a simplified analytical model. Each solution is added using the principle of superposition, which allows for the building a nodal network in which each node corresponds to a temperature. In this paper, the method used by Hellström is adapted to electrical wire harnesses with many adaptions and comparisons to commercial modeling software.

\subsection{Hypothesis and objectives}

To adapt this problem to a bundle layout, the study has been carried out in a steady-state in a slice of wire bundle (2D study) in which the physical characteristics of the materials are independent of the temperature. Each wire is modeled by an infinite cylinder surrounded by an annulus that represent respectively the core and the insulation (example in Fig. 1(a) and Fig. 6 for two and ten wires, respectively). We consider a tight harness with small air cavities. If the buoyancy forces created by the heat flow through these air cavities cannot overcome the viscous forces [27], then the air trapped in the winding is supposed to be motionless. Convection can be neglected which is ensured by a low number of Rayleigh i.e. $R a<1708$. So, the model considers only the conductive equation for thermal transfers. We do not consider internal radiation between wires. The number of wires is unlimited, and each wire can have different thermal characteristics. Furthermore, we have considered only radial thermal fluxes.

The industrial goal is to solve numerous layouts and power sets. This model makes it possible to quickly

75 solve random layouts that correspond to the production process where the layout of the wires is neither mastered nor known.

\subsection{Course of the article}

The focus of this study is the uses and limitations of the superposition principle when many thermal sources are compact in bundle wires. The ILS model from Hellström's study [18] is adapted for a bundle problem. First, the model is described for two wires and is solved using an adapted linear resolution. A faster matrix resolution is developed to obtain an $N$-wire model. This resolution is adapted to be computer friendly. To test the adaptability of this model, the first cases address only the use of two wires. These initial trials show 
difficulties with very simple cases. Here, the wires are arranged symmetrically and have the same geometrical and thermal characteristics. Two power situations are studied and are contrasted with the results from the commercial software Ansys Fluent (used in conduction only i.e. no CFD). These first results are good but show some limitations. The following section presents a more representative case of 10 wires. The comparison with this case resolved with ANSYS FLUENT reveals the first limits. In the last section of this paper, the nodal model has been improved with an equivalent conductivity of each wire.

\section{Nodal network method}

The ILS model is used by Hellström[18] to describe geothermal storage. It has been solved using an equation Eq. (1) of an infinite line source in an infinite cylindrical medium. This equation is used for each source. Each source is powered separately. For each equation, the temperature field is solved at any domain point. The temperature at each wire position is known. Thanks to the superposition principle and Kirchhoff's laws, a fully connected nodal network was created. Each source is a node, and they are all interconnected.

The differences and adjustments between the geothermal model and the harness model are:

- the different scale: the wires have diameters of only a few Millimeters, whereas the borehole used by Hellström are around $15 \mathrm{~cm}$ in diameter.

- the geothermal sources are contained in a composite region: in our case, this is just one region (confined air).

- In the geothermal study, the pipes have fluid with uniform temperature. Here the fluid becomes a wire core, which can be considered as uniform in temperature because the copper thermal conductivity is much higher than in confined air $\left(\lambda_{\text {copper }}=380 \mathrm{~W} \cdot \mathrm{m}^{-1} \cdot \mathrm{K}^{-1}\right.$ and $\left.\lambda_{\text {air }}=0.025 \mathrm{~W} \cdot \mathrm{m}^{-1} \cdot \mathrm{K}^{-1}\right)$.

The retained assumptions are that the physical characteristics of the materials are temperature independent and line source approximations. One wire is represented by a line source for one superposition. To find a simple analytical resolution, the core material is disregarded for each superposition. The effect of insulation on heat exchange is added on the powered wire only, to the solution due to thermal resistance of radial conduction in the cylindrical wall. The insulation effects are obtained directly in the analytical equation without adding additional resistances in the nodal network. The boundary condition at the radius $r_{b}$ is an average of distributed temperature in the analytical equation on this radius $\left(T_{b}\right)$ [18]. It is a Dirichlet condition. Figure $1(\mathrm{a})$ and $1(\mathrm{~b})$ show a simple problem with only two wires.

The description of the nodal model is broken down into three steps. The first step is to write an analytic equation. The second step is to set up a 2-wire nodal network, and the last step is to determine an efficient nodal network established for $N$-wires.

\subsection{Analytic model}

ILS modeling uses the superposition principle. For each superposition, only one wire is powered. It is represented by a line source. Every notion of analytic equation and superposition is described for a 2-wire resolution in Figure 2. 


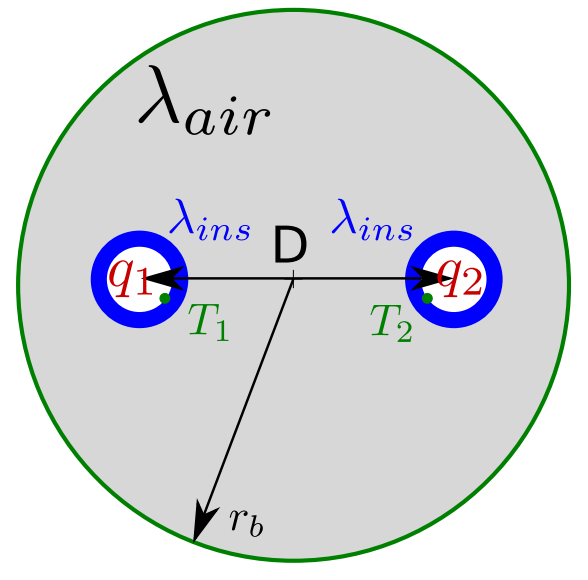

(a) Presentation of the variables of the study

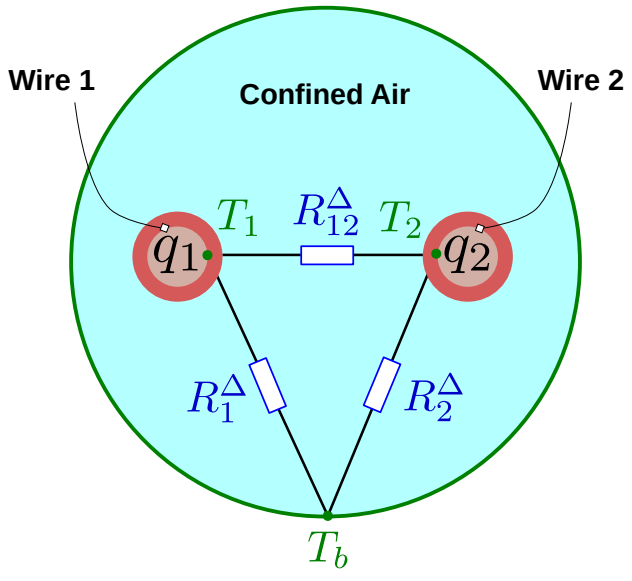

(b) Problem using network method for two thermal sources

Figure 1: Problem with two wires and the corresponding nodal network
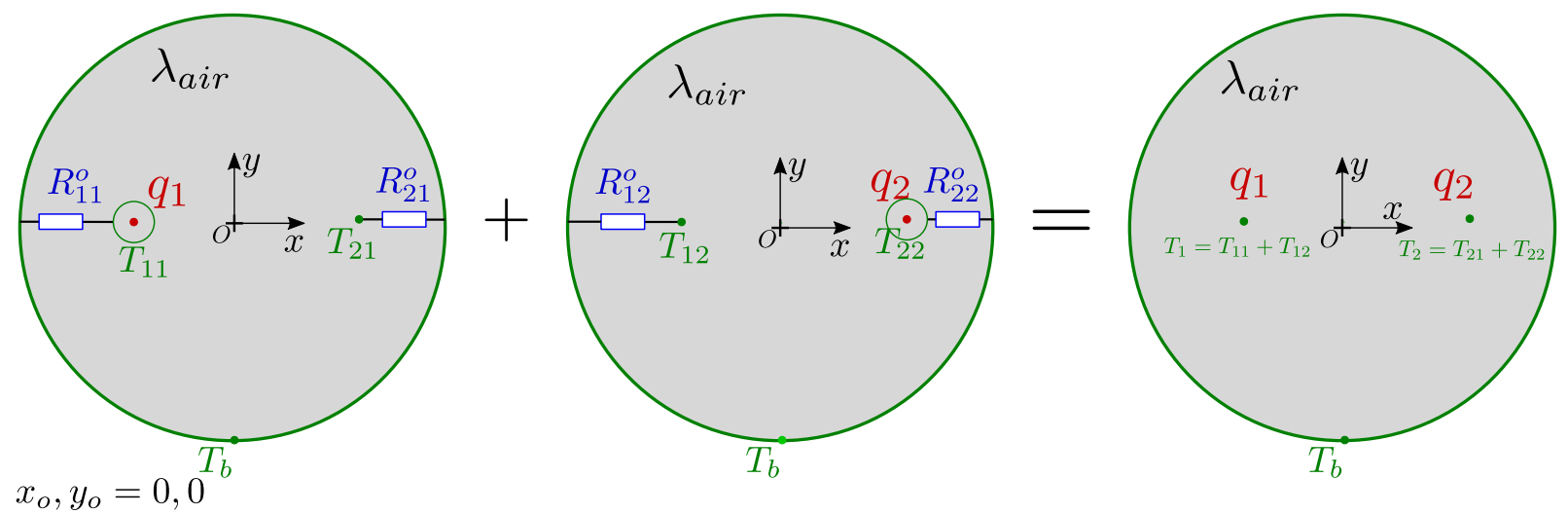

Figure 2: Method to find thermal resistance $R^{o}$ and superposition application. The full solution is the sum of the cases with only one wire powered.

Each temperature of each superposition $T_{m n}$ is obtained via Eq. (1) with $m$ indicating the studied wire and $n$ designating the powered wire. So in Figure 2, the temperature $T_{1}$ results from $T_{11}$ and $T_{12}$. Additionally this procedure allows to identify thermal resistances $R^{o}$ Eq. (2) and (3).

$$
T_{m n}=q_{n} \times \frac{1}{2 \pi \lambda_{\text {air }}} \cdot \ln \left(\frac{r_{b}}{\sqrt{\left(x_{m}-x_{n}\right)^{2}+\left(y_{m}-y_{n}\right)^{2}}}\right)+T_{b}
$$

and $\Delta T_{m n}=T_{m n}-T_{b}=q_{n} \times R_{m n}^{o}$ so

$$
R_{m n}^{o}=\frac{1}{2 \pi \lambda_{a i r}} \cdot \ln \left(\frac{r_{b}}{\sqrt{\left(x_{m}-x_{n}\right)^{2}+\left(y_{m}-y_{n}\right)^{2}}}\right)
$$

With Eq. (2), $R_{n n}^{o}$ cannot be determined. There is a division by zero in the equation because the temperature at the source position is infinite. As described by Hellström [18], when $m=n$, the temperature is taken at the interface between insulation and core and the thermal resistance of the insulation $R_{i n s, n}$ is summed up to 
obtain $R_{n n}^{o}$ :

$$
R_{n n}^{o}=\frac{1}{2 \pi \lambda_{\text {air }}} \cdot \ln \left(\frac{r_{b}}{r_{c o r, n}}\right)+\underbrace{\left.\frac{1}{2 \pi \lambda_{i n s, n}} \cdot \ln \left(\frac{r_{i n s, n}}{r_{c o r, n}}\right)\right)}_{R_{\text {ins }, n}}
$$

The temperature $T_{m n}$ at the point $m$ is known for each superposition $n$ ( $n$ between 1 and $N$ ). According to the superposition principle, the sum of all these temperatures gives the temperature $T_{m}$ at the point $m$ when all the wires are powered Eq. (5). This equation written for all wires ( $m$ between 1 and $M$ ) gives a linear system.

$$
\begin{aligned}
\Delta T_{m} & =\sum_{n=1}^{N} \Delta T_{m n}=\sum_{n=1}^{N}\left(T_{m n}-T_{b}\right) \\
\Delta T_{m} & =\sum_{n=1}^{N} q_{n} \times R_{m n}^{o}
\end{aligned}
$$

\subsection{Establishment of a nodal network for two wires}

In this section, we impose a fully connected nodal network, and we will find realistic thermal resistances $R^{\Delta}$. It should be noted that the $R^{\Delta}$ differs from the $R^{o}$ resistances. The 2 -wire layout and the associated nodal network are depicted in Figure 3.

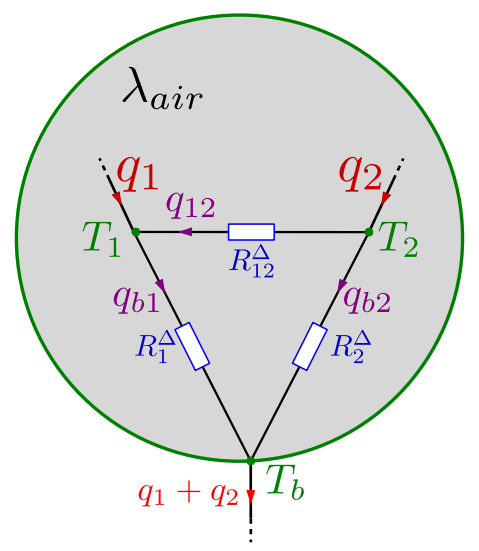

Figure 3: Nodal thermal network (chosen arbitrarily) - Sources and boundary are fully connected to each other

Initially, the $R^{\Delta}$ thermal resistances that are unknowns must be identified and calculated as a function of the $R^{o}$. For a two-wire case, the system becomes Eq. (6) via Kirchhoff's point rules.

$$
\left\{\begin{array}{l}
q_{1}=\frac{1}{R_{1}^{\Delta}}\left(T_{1}-T_{b}\right)+\frac{1}{R_{12}^{\Delta}}\left(T_{1}-T_{2}\right) \\
q_{2}=\frac{1}{R_{2}^{\Delta}}\left(T_{1}-T_{b}\right)+\frac{1}{R_{21}^{\Delta}}\left(T_{2}-T_{1}\right)
\end{array}\right.
$$

The goal is to use the ILS equation and the superposition principle to obtain the previous nodal network. More precisely, the resistance between every wire is $R_{m n}^{\Delta}$ and between a wire and the boundary is $R_{m}^{\Delta}$. Using Eq. (2-5), we can write the final temperature rises $\Delta T_{i}$ for each wire as Eq. (7) and the analytical resistance as Eq. (8).

$$
\left\{\begin{array} { l } 
{ \Delta T _ { 1 } = \Delta T _ { 1 1 } + \Delta T _ { 1 2 } } \\
{ \Delta T _ { 2 } = \Delta T _ { 2 1 } + \Delta T _ { 2 2 } }
\end{array} \leftrightarrow \left\{\begin{array}{l}
\Delta T_{1}=q_{1} \times R_{11}^{o}+q_{2} \times R_{12}^{o} \\
\Delta T_{2}=q_{1} \times R_{21}^{o}+q_{2} \times R_{22}^{o}
\end{array}\right.\right.
$$




$$
\begin{array}{r}
R_{11}^{o}=\frac{1}{2 \pi \lambda_{\text {air }}} \times \ln \left(\frac{r_{b}}{r_{\text {cor }, 1}}\right)+\frac{1}{2 \pi \lambda_{\text {ins }, n}} \times \ln \frac{r_{\text {ins }, 1}}{r_{\text {cor }, 1}} \\
R_{22}^{o}=\frac{1}{2 \pi \lambda_{\text {air }}} \times \ln \left(\frac{r_{b}}{r_{\text {cor }, 2}}\right)+\frac{1}{2 \pi \lambda_{\text {ins }, n}} \times \ln \frac{r_{\text {ins }, 2}}{r_{\text {cor }, 2}} \\
R_{12}^{o}=R_{21}^{o}=\frac{1}{2 \pi \lambda_{\text {air }}} \times \ln \left(\frac{r_{b}}{\sqrt{\left(x_{2}-x_{1}\right)^{2}+\left(y_{2}-y_{1}\right)^{2}}}\right)
\end{array}
$$

A linear resolution is applied to Eq. (7) and $q_{1}$ and $q_{2}$ are separated:

$$
\left\{\begin{array}{l}
q_{1}=\frac{R_{22}^{o}-R_{12}^{o}}{R_{11}^{o} \cdot R_{22}^{o}-\left(R_{12}^{o}\right)^{2}}\left(T_{1}-T_{b}\right)+\frac{R_{12}^{o}}{R_{11}^{o} \cdot R_{22}^{o}-\left(R_{12}^{o}\right)^{2}}\left(T_{1}-T_{2}\right) \\
q_{2}=\frac{R_{11}^{o}-R_{12}^{o}}{R_{11}^{o} \cdot R_{22}^{o}-\left(R_{12}^{o}\right)^{2}}\left(T_{2}-T_{b}\right)+\frac{R_{12}^{o}}{R_{11}^{o} \cdot R_{22}^{o}-\left(R_{12}^{o}\right)^{2}}\left(T_{2}-T_{1}\right)
\end{array}\right.
$$

The network resistances $R^{\Delta}$ have been identified from Eq. (6) and Eq. (9):

$$
R_{1}^{\Delta}=\frac{R_{11}^{o} R_{22}^{o}-\left(R_{12}^{o}\right)^{2}}{R_{22}-R_{12}} \quad R_{2}^{\Delta}=\frac{R_{11}^{o} R_{22}^{o}-\left(R_{12}^{o}\right)^{2}}{R_{11}-R_{12}}
$$

Eq. (10) shows the connection between $R^{\Delta}$ and $R^{o}$ for a simple example (see Fig. 3). Generalization for a $N$-wire configuration will be explained in the next section.

\subsection{Matrix method with $N$-wires}

The establishment of the nodal network method is usable for more wires. The superposition principle creates a linear problem. It enables for every source alone to sum every temperature field. Equation 5 can be written using matrix equation (Eq. (11)) with $[q]$ sources vector $q_{i},[\Delta T]$ heating vector between a wire and the boundary and $\left[R^{o}\right]$ matrix of analytical resistances.

$$
[\Delta T]=\left[R^{o}\right] \cdot[q]
$$

The goal is to find every thermal resistances $R^{\Delta}$. Equation (12) is the extension of Eq. (6) for a $N$-wires case. Equation (12) is written by applying the Chasles relation $T_{i}-T_{j}=\left(T_{i}-T_{b}\right)-\left(T_{j}-T_{b}\right)$.

$$
\left\{\begin{array}{cc}
q_{1}= & \frac{T_{1}-T_{b}}{R_{1}^{\Delta}}+\frac{T_{1}-T_{b}}{R_{12}^{\Delta}}-\frac{T_{2}-T_{b}}{R_{12}^{\Delta}}+\cdots+\frac{T_{1}-T_{b}}{R_{1 N}^{\Delta}}-\frac{T_{N}-T_{b}}{R_{1 N}^{\Delta}} \\
\vdots & \vdots \\
q_{i}= & \frac{T_{i}-T_{b}}{R_{i}^{\Delta}}+\frac{T_{i}-T_{b}}{R_{i 1}^{\Delta}}-\frac{T_{1}-T_{b}}{R_{i 1}^{\Delta}}+\cdots+\frac{T_{i}-T_{b}}{R_{i N}^{\Delta}}-\frac{T_{N}-T_{b}}{R_{i N}^{\Delta}} \\
\vdots & \vdots \\
q_{N}= & \frac{T_{N}-T_{b}}{R_{N}^{\Delta}}+\frac{T_{N}-T_{b}}{R_{N 1}^{\Delta}}-\frac{T_{1}-T_{b}}{R_{N 1}^{\Delta}}+\cdots+\frac{T_{N}-T_{b}}{R_{(N-1) N}^{\Delta}}-\frac{T_{N-1}-T_{b}}{R_{(N-1) N}^{\Delta}}
\end{array}\right.
$$

Using the system of equations, we can isolate the thermal sources $q_{i}$ and the different heating $\Delta T_{i}$, and 
deduce the matrix Eq. (13). The term noted $[P]$ contains the different resistances $R^{\Delta}$ (see Eq. $(14,15)$ ).

$$
[P]=\left[\begin{array}{cccccc}
P_{11} & -\frac{1}{R_{12}^{\Delta}} & \cdots & -\frac{1}{R_{1 i}^{\Delta}} & \cdots & -\frac{1}{R_{1 N}^{\Delta}} \\
-\frac{1}{R_{12}^{\Delta}} & P_{22} & & & & -\frac{1}{R_{2 N}^{\Delta}} \\
\vdots & & \ddots & & & \vdots \\
-\frac{1}{R_{1 i}^{\Delta}} & & & P_{i i} & & -\frac{1}{R_{i N}^{\Delta}} \\
\vdots & & & & \ddots & \vdots \\
-\frac{1}{R_{1 N}^{\Delta}} & \cdots & \cdots & \cdots & \cdots & P_{N N}
\end{array}\right]
$$

with

$$
P_{i i}=\frac{1}{R_{i}^{\Delta}}+\sum_{k=1, k \neq i}^{N} \frac{1}{R_{i k}^{\triangle}}
$$

Finding the matrix $[P]$ values and deducing the $R_{i j}^{\Delta}$ values can be done easily. With Eq. (11) and Eq. (13) the matrix $[P]$ is the inverse of $\left[R^{o}\right]$ :

$$
\left[R^{o}\right]=[P]^{-1}
$$

To avoid the matrix inversion, $R^{\Delta}$ is found with a faster resolution using an additional matrix $[S]$, and this yields Eq. (17):

$$
\left[R^{o}\right] \cdot[P] \cdot[S]=[S]
$$

with $[S]$ as follows:

$$
[S]=\left[\begin{array}{ccccc}
1 & 0 & \cdots & \cdots & 0 \\
\vdots & -1 & \ddots & & \vdots \\
1 & 0 & \ddots & \ddots & \vdots \\
\vdots & \vdots & \ddots & \ddots & 0 \\
1 & 0 & \cdots & 0 & -1
\end{array}\right]
$$

In Equation 17 the product $[P] \cdot[S]$ could be considered as the unknowns and $[S]$ as the right hand side of a linear system. This system is then solved via a Gaussian Elimination method. Once $[P] \cdot[S]$ determined, it became apparent that certain values of $(P \cdot S)_{i j}$ are the inverse values of the elements of $R_{i j}^{\Delta}$ (see Eq. (19- 20)).

$$
\begin{aligned}
(P \cdot S)_{i j, j=1} & =\left(R_{i}^{\Delta}\right)^{-1} \\
(P \cdot S)_{i j, j \neq 1 \text { and } i \neq j} & =\left(R_{i j}^{\Delta}\right)^{-1}
\end{aligned}
$$

With an established nodal network where all resistances are known and Kirchhoff's laws, the temperature and different heat fluxes between each node can be solved via graph theory [28, 29, 30]. This theory uses Kirchhoff's point rule. Equation (21) represents a conservation energy law to each node (Kirchhoff's point rule) 
with the unknown temperature vector $[T]$, known thermal sources vector $[Q]$ and matrix $[M]$ which represents the structure of the network formed by the wire layout (Incidence matrix [31]) and the elements of this matrix $[M]$ are weighted by the inverse of thermal resistances $R_{i j}^{\Delta}$.

$$
[M] \cdot[T]=[Q]
$$

The size of the matrices and the system is fixed by the number of nodes. The vector size $[T]$ for $\mathrm{N}$ wires is $\mathrm{N}$ elements. The matrix $[M]$ is a square and sparse matrix of size $N \times N$.

\section{Comparison with the commercial software Ansys Fluent}

The method developed is compared to Finite Volume Methods (FVM) used in Ansys Fluent. The domain

\subsection{First case study: two symmetrical wires}

The effect of the distance between two wires is studied using symmetrical dispositions. Two typical power$$
\text { b }
$$

\footnotetext{
define the domain of validity of the mathematical model used and to find its limits.
}

Table 1: Thermal and electrical parameters of nodal method and FLuENT profiles in a vehicle (PA and PB) are studied.

- Profile A (PA) with both wires powered at $1 \mathrm{~A}$.

- Profile B (PB) with the two wires powered at $1 \mathrm{~A}$ and $10 \mathrm{~A}$, respectively.

The thermal power generated by each wire is calculated by the Joule effect. The electrical resistivity $\rho_{\text {elec }}$ is used to calculate all electrical resistances. Furthermore, we focus on two geometrical parameters: the distance between the two wires $(D)$ and the size of the whole domain (i.e. radius $r_{b}$ ). This study makes it possible to 


\subsubsection{Sensitivity analysis at the gap between the two wires.}

This section presents the variation of distance $(D)$ between the two wire centers from $4 \mathrm{~mm}$ to $96 \mathrm{~mm}$, with a fixed value for $r_{b}(50 \mathrm{~mm}$ ). The setup (stated as 1) used is summarized in Table 2. The $4 \mathrm{~mm}$ distance between centers represents two wires which are almost in contact. It is a typical distance in multi-wire harnesses.

\begin{tabular}{cccc}
\hline \hline Symbol & Parameters & Setup 1 & Setup 2 \\
\hline$r_{b}$ & Domain radius & $50 \mathrm{~mm}$ & 4.5 to $90 \mathrm{~mm}$ \\
$T_{b}$ & Temperature set at $r_{b}$ & $50{ }^{\circ} \mathrm{C}$ & $50{ }^{\circ} \mathrm{C}$ \\
$r p_{i}$ & Radius of each core & $1.5 \mathrm{~mm}$ & $1.5 \mathrm{~mm}$ \\
$r p_{o}$ & Outer radius (core + insulation) & $2.0 \mathrm{~mm}$ & $2.0 \mathrm{~mm}$ \\
$D$ & Distance between the two centers of core & 4 to $96 \mathrm{~mm}$ & $5 \mathrm{~mm}$ \\
$I$ & Electric current in each wire & PA or PB & PA or PB \\
\hline \hline
\end{tabular}

Table 2: Geometrical Parameters of Nodal Method and Fluent

Figure 4 shows that the curves are similar in both methods when the distance $D$ does not exceed the domain radius $r_{b}$. When $D$ exceeds the radius $r_{b}$, the network method is no more in agreement with FLuENT. In the first power case (Fig. $4 \mathrm{PA}$ ), we could observe a small gap between the two methods (less than $0.03^{\circ} \mathrm{C}$ ). In the second power case (Fig. $4 \mathrm{~PB}$ ), a temperature difference (up to $4{ }^{\circ} \mathrm{C}$ ) increases when $D$ exceeds $30 \mathrm{~mm}$. So the difference between FLuENT and nodal method is maximum when the two wires are close to the boundary. These results validate the model when a minimal distance is kept between the two wires or between one wire and the boundary.
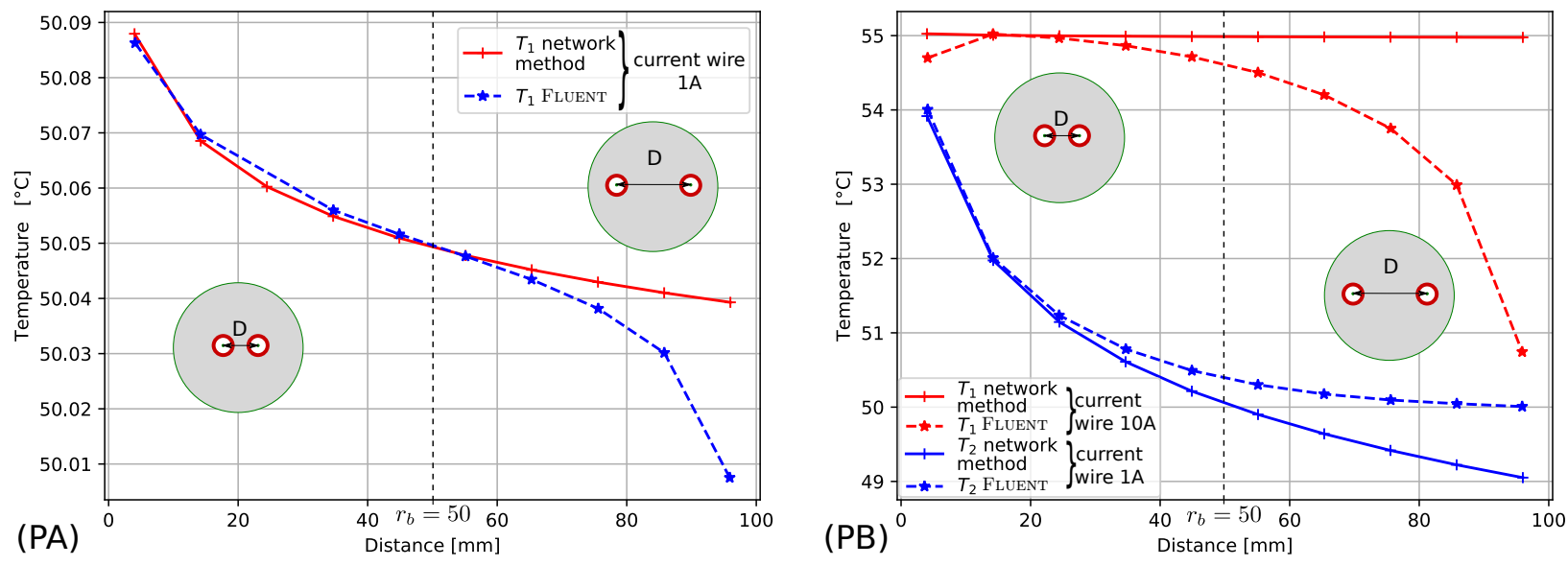

Figure 4: Temperatures against distance $D$ (Setup 1) obtained with the same thermal power in each wire (PA) and for different powers $(\mathrm{PB})$.

\subsubsection{Sensitivity analysis for the distance from the boundary}

Setup 2 is summarized in Table 2. $D$ is set at $5 \mathrm{~mm}$ with a range for $r_{b}=4.5$ to $10 \mathrm{~mm}$. For all cases, the temperature (Fig. 5) increases with $r_{b}$. When the boundary with the Dirichlet condition set at $T_{b}$ is moved away, the thermal insulation of the wires increases, and consequently, the temperature increases. A slight gap between FLUENT and the nodal method can be observed and is hard to explain. The next step examines a simulation 
case with 10 wires quite compacted.
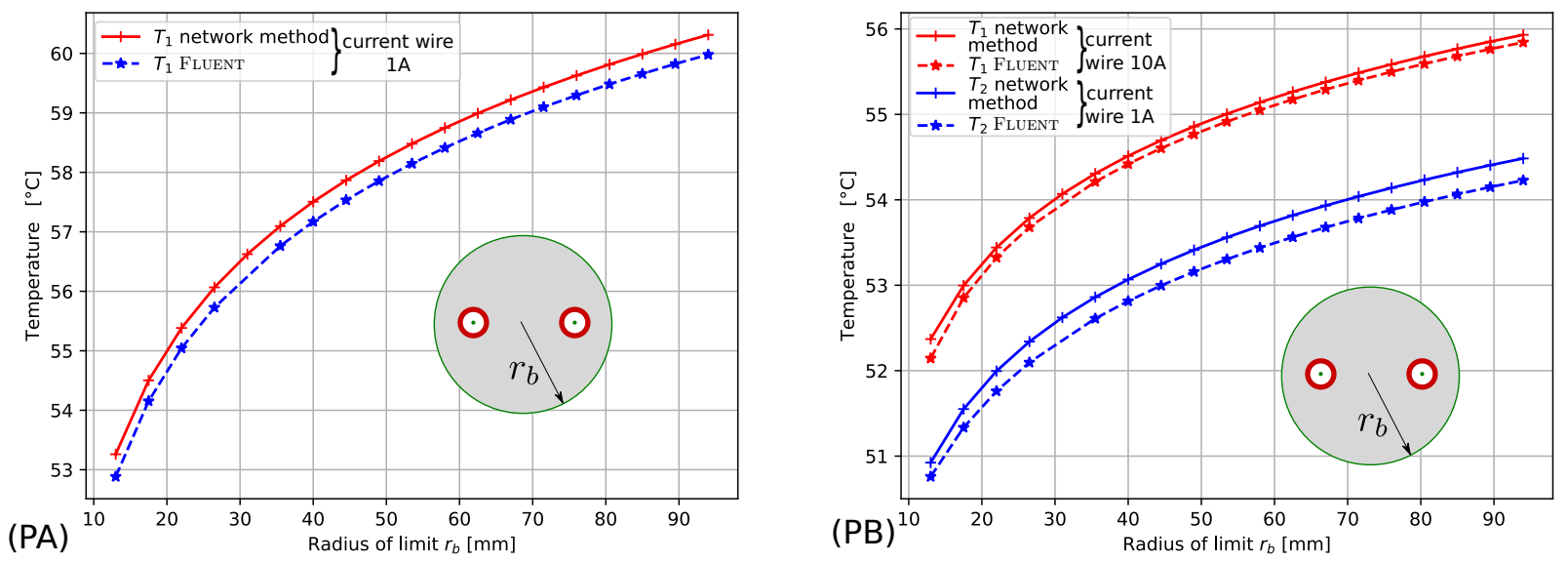

Figure 5: Temperatures against the radius of the reference $r_{b}$ (Setup 2) obtained using the same thermal power (PA) and different powers (PB).

\subsection{Case study: a 10 wire harness}

This resolution must show the nodal method's efficiency to find the right core temperature on a compact multi-sources problem. The ten wires are composed of three different types. They all have the same thermal and electrical characteristics (Table 1). The disposition has been selected randomly and the wire power has been arbitrarily imposed (Table 3 and Fig 6). These values represent minimal, nominal and critic currents which can exist in a vehicle.

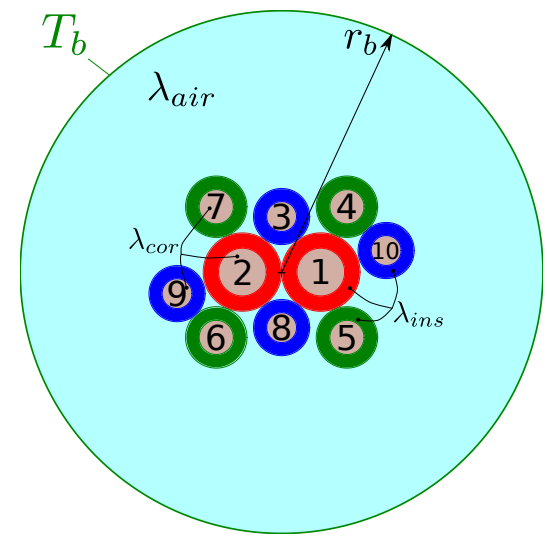

Figure 6: Case study with 10 thermal sources and a tight layout

\begin{tabular}{ccccccc}
\hline \hline $\begin{array}{c}\text { Wire } \\
\text { index }\end{array}$ & Position & $\begin{array}{c}\text { Core } \\
\text { radius }\end{array}$ & $\begin{array}{c}\text { Outer } \\
\text { radius }\end{array}$ & $\begin{array}{c}\text { Elec. } \\
\text { current }\end{array}$ & $\begin{array}{c}\text { Heat } \\
\text { source }\end{array}$ \\
\hline & $x$ & $y$ & $r p_{i}$ & $r p_{o}$ & $I$ & $q$ \\
& $m m$ & $m m$ & $m m$ & $m m$ & $A$ & $W$ \\
1 & 1.2 & 0 & 0.73 & 1.2 & 10 & 1.0154 \\
2 & -1.2 & 0 & 0.73 & 1.2 & 15 & 2.2847 \\
3 & 0 & 1.7 & 0.4575 & 0.86 & 0.1 & 0.0003 \\
4 & 2 & 2 & 0.523 & 0.94 & 1 & 0.0198 \\
5 & 2 & -2 & 0.523 & 0.94 & 0.8 & 0.0127 \\
6 & -2 & -2 & 0.523 & 0.94 & 1.2 & 0.0285 \\
7 & -2 & 2 & 0.523 & 0.94 & 1.3 & 0.0334 \\
8 & 0 & -1.7 & 0.4575 & 0.86 & 0.5 & 0.0065 \\
9 & -3.25 & -0.64 & 0.4575 & 0.86 & 0.3 & 0.0023 \\
10 & 3.25 & 0.64 & 0.4575 & 0.86 & 0.2 & 0.0010 \\
\hline \hline
\end{tabular}

Table 3: Case study with 10 thermal sources and a tight layout. fixed, while the radius $r_{b}$ will vary. Using the matrix approach developed in 2.3, this multi-sources problem is solved in a few seconds while it takes several minutes in Fluent. The $r_{b}$ range starts at $10 \mathrm{~mm}$ to stay in a functional domain. Indeed, $r_{b}=4.18 \mathrm{~mm}$ is the minimum value to prevent any collision between the wires and 
the boundary. The temperature distribution is coherent with regard to power and the position of the thermal

(A)

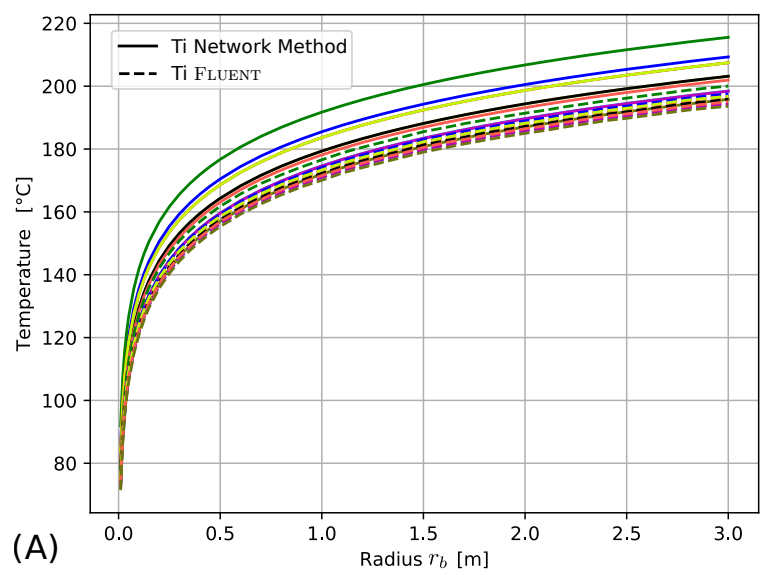

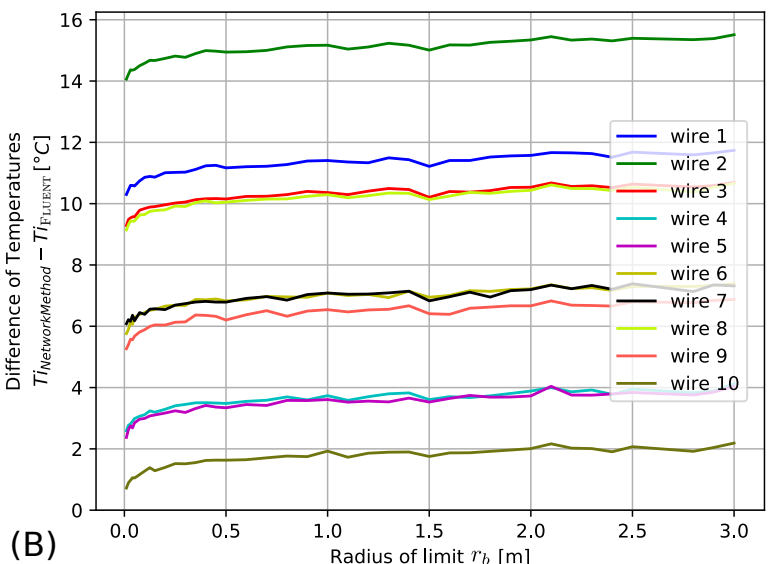

(B)

. (A) level of temperature for each thermal source for each method. (B) difference between the temperature level of each method.

Figure 7: Result of comparison of Network method and FLUENT

The nodal method compared with FLUENT gives the same qualitative results: temperature ranking remains the same. However, the quantitative results are not equal. Results from the nodal method are systemically higher than the result from Fluent (up to $15^{\circ} \mathrm{C}$ for wire 2). These differences are due to the application of line source approximation. They are accumulated with the superposition principle. Notably, the line source approximation solves the problem in a single domain where the core and insulation materials in wires are disregarded. In compact multi-sources problem, this assumption creates a problem on the thermal conductivity. The absence of a material with a higher conductivity than air distorts the heat release. A first part is corrected in Hellström's thesis [18] where insulation is added as network thermal resistance Eq. (3).

\subsection{Study of the effect of superposition}

This is highlighted by two simple FuUent cases. In case A, wire 1 is powered and surrounded by all wires, while in case B, it is powered without any wire but with just conductive air (Fig. 8). The temperature in case (A) is more distributed in each neighboring wire. Case (A) represents real distribution, while case (B) represents a superposition of the models. Notably, in case B the heat flux is contained in the wire core, so that the temperature level is higher than in case A. The thermal bridging created by the wire core is not present and we can observe a hot spot in the temperature field (up to $4{ }^{\circ} \mathrm{C}$, as seen in Fig. 8). If each model used in the superposition process produces a hot spot, the summation will induce a result, as shown in Figure 7B. Throughout this study, the pertinence of using an equivalent conductivity to correct this gap has been examined. 


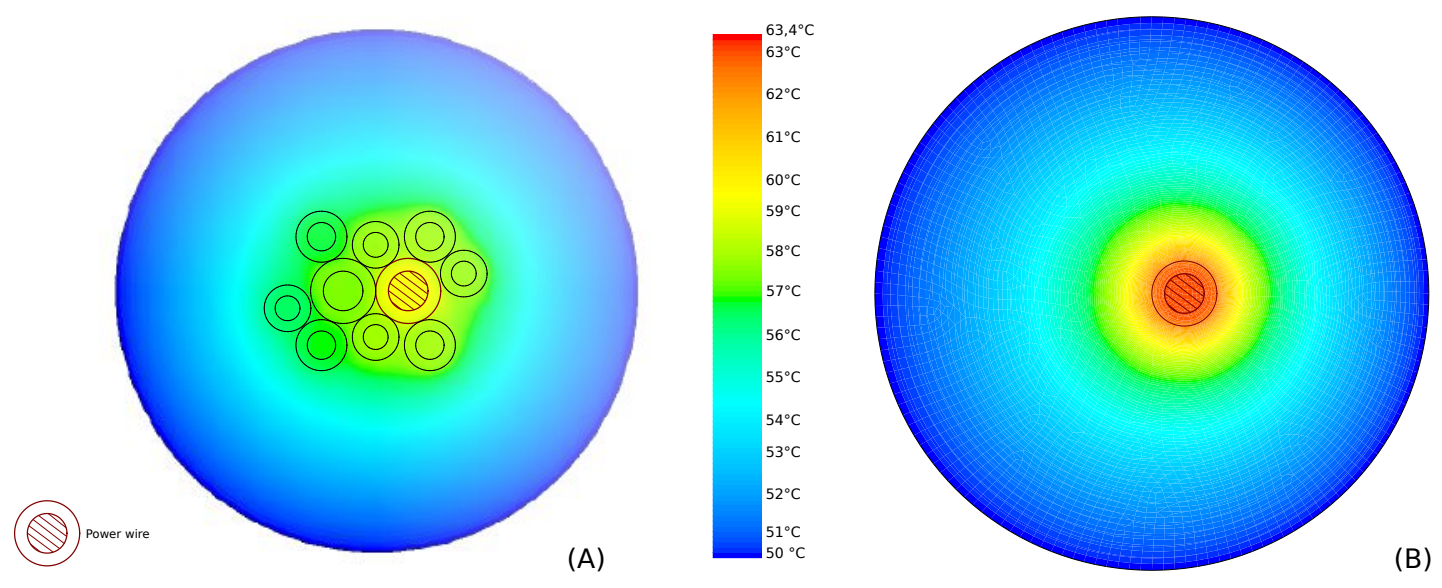

Figure 8: (A) wire $\mathrm{N}^{\circ} 1$ is powered and surrounded by all wires. (B) wire $\mathrm{N}^{\circ} 1$ is powered and surrounded by air.

\section{Conductivity for compact ILS}

In Figure 8, FLUENT highlights the origin of the gap. A way to obtain better results is to consider that each wire is surrounded by a conductive medium. Several equivalent thermal conductivities have been tried in the nodal method. These conductivities have been calculated from models that are primarily used to study winding heads of electric machines [23] (see section 4.1). Finally an optimization process is used to fit FuUENT data (see 4.2).

\subsection{Implementation of equivalent conductivities}

To find equivalent conductivities, the models use multiple cylinders called inclusions. These inclusions have the same thermal characteristics but are made of medium with a very different thermal conductivity. Only the core material and the confined air are considered, except for the Mori and Tanaka Model [33]. In these cases, the thermal resistance of the insulation is added to the nodal network [18].

- The Perrins et al. Model [34]: they have developed equations to consider one homogeneous medium instead of two heterogeneous media. These equations give an equivalent conductivity for a square and hexagonal cylinder's disposition.

- The Hashin and Shtrikman Model (H\&S Model) [35]: Their research was inspired by Voigt [36] and Reuss [37]. They studied equivalent properties of multiphase materials composed of two homogeneous and isotropic phases. Hashin and Shtrikman established a model based on microstructure inclusions with different sizes. This model estimates an equivalent thermal conductivity via each material surface ratio $\tau$ and each thermal conductivity $\lambda$ Eq. (22).

$$
\lambda_{e q}=\lambda_{a i r} \frac{\left(1+\tau_{c o r}\right) \lambda_{c o r}+\left(1-\tau_{c o r}\right) \lambda_{a i r}}{\left(1-\tau_{c o r}\right) \lambda_{c o r}+\left(1+\tau_{c o r}\right) \lambda_{a i r}}
$$

- Milton Model [38]: Milton has developed a model where the homogenization needs an additional parameter. This geometrical parameter $\zeta$ is linked to the disposition of inclusions. Torquato and Lado [39] have given many values of $\zeta$ for different dispositions. In this case, Torquato and Lado give an adapted geometrical parameter for random cylinder inclusion. 
- Mori and Tanaka Model (M\&T Model) [33]: This model determines an homogeneous equivalent parameter for three phases. Media as the first phase, and inclusion composited with two other phases. Like Hashin and Shtrikman, this model is determined from each surface $\tau$ rate, and each thermal conductivity $\lambda$ of materials. Eq. (23).

$$
\lambda_{e q}=\lambda_{a i r} \frac{\tau_{c o r}\left[2 \cdot \lambda_{c o r}\left(\lambda_{a i r}+\lambda_{i n s}\right)\right]+\tau_{a i r}\left[\left(\lambda_{a i r}+\lambda_{\text {ins }}\right)\left(\lambda_{\text {air }}+\lambda_{\text {cor }}\right)\right]+\tau_{\text {ins }}\left[2 \cdot \lambda_{\text {ins }} \times\left(\lambda_{\text {air }}+\lambda_{\text {cor }}\right)\right]}{\tau_{c o r}\left[2 \cdot \lambda_{\text {air }}\left(\lambda_{\text {air }}+\lambda_{\text {ins }}\right)\right]+\tau_{\text {air }}\left[\left(\lambda_{\text {air }}+\lambda_{\text {cor }}\right)\left(\lambda_{\text {air }}+\lambda_{\text {ins }}\right)\right]+\tau_{\text {ins }}\left[2 \cdot \lambda_{\text {ins }}\left(\lambda_{\text {ins }}+\lambda_{\text {cor }}\right)\right]}
$$

Each model is compared in the value range of the study (Fig. 9). The value range is given by the external limit radius. Here the minimum radius is $4.20 \mathrm{~mm}$, which corresponds to a surface ratio of copper of $17 \%$. The M\&T Model uses the surface rates of the core, insulation, and air. The resulting surface is shown in Figure 6. However, the equivalent thermal conductivity from Perrin, Milton, and H\&S Models is not comparable with the conductivity of the M\&T model. The M\&T model considers the presence of insulation directly, while in the others, the insulation is added via nodal resistance. Thus, the evolution of M\&T curves is faster because it takes into account the insulation effects. The first four listed models are similar with a copper surface ratio ranging from 0 to $30 \%$. The limit $r_{b}$ must be higher than $4.2 \mathrm{~mm}$ for all the wires to be contained in the domain. To respect this, the surface ratio of the core has to lower as $17 \%$. In this case, the curves of the Perrin, H\&S, and Milton models overlap, so the equivalent conductivity selected and applied in ILS method is only H\&S Model and M\&T Model. The found thermal conductivities from equivalent models and their associated results are presented in Table 4 and Figure 9 (red and green bar).

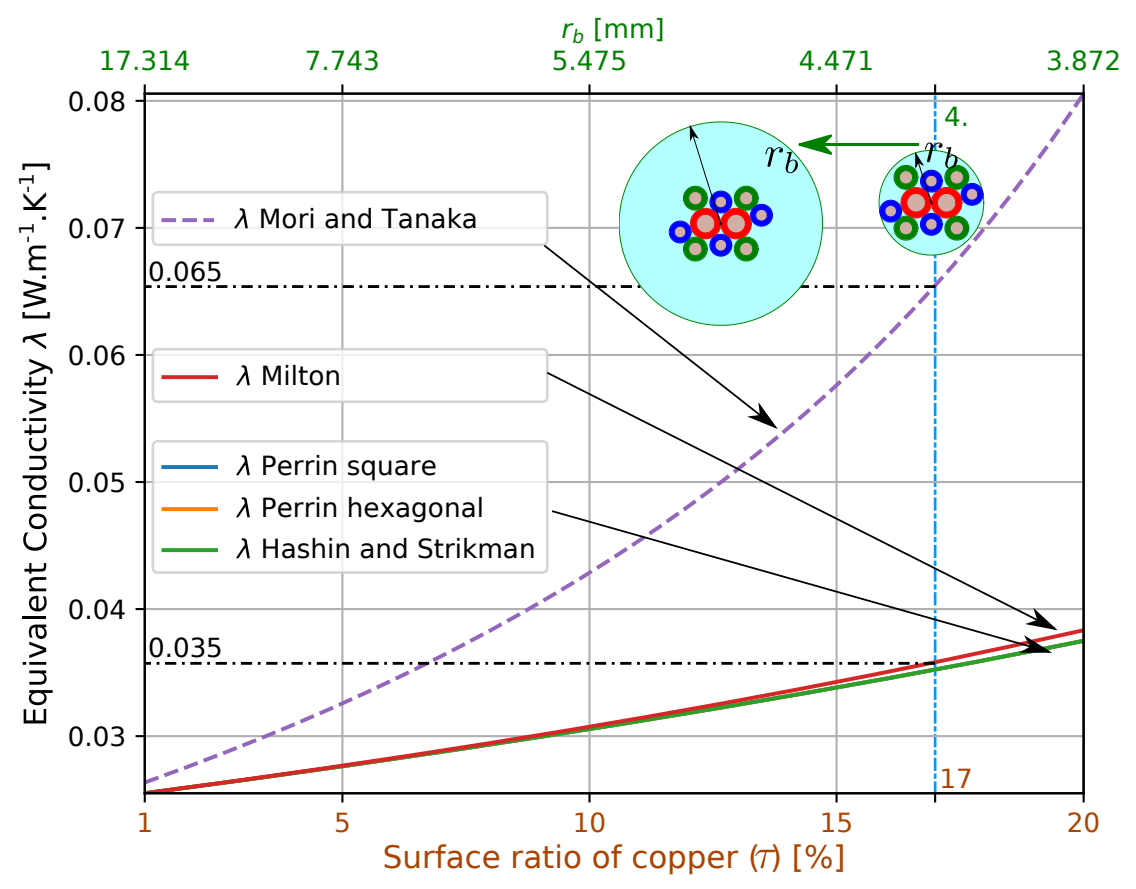

Figure 9: Comparison for different models of equivalent conductivity

\subsection{Optimization of thermal conductivity using Ansys Fluent}

To obtain similar results between FLUENT and nodal model, several configurations of thermal conductivity can exist. An optimization is performed using the non-linear least squares method [40] associated with the Trust 
Region reFlective method ('TRF' method) [41] to determine the adequate thermal conductivities.

In our case, we could determine an overall equivalent thermal conductivity i.e. one value $\lambda_{\text {opt }}$ for all the wires or consider that each wire has its own surrounding with a specific thermal conductivity i.e. $\lambda_{i, \text { opt }}$ for the

The optimization is performed for just one value and gives $\lambda_{\text {opt }}=0.0691 \mathrm{~W} \cdot \mathrm{m}^{-1} \cdot \mathrm{K}^{-1}$ (Table 4 ). This value is close to the equivalent conductivity stipulated in the literature, especially for the M\&T model (Table 4).

Individual values of thermal conductivity $\lambda_{i, \text { opt }}$ are within the range of 0.025 to $0.1998 \mathrm{~W} \cdot \mathrm{m}^{-1} \cdot \mathrm{K}^{-1}$, with a mean value of $0.065 \mathrm{~W} \cdot \mathrm{m}^{-1} \cdot \mathrm{K}^{-1}$. The rank of the values tested in increasing order is not exclusively linked to the limit distance or power of the sources. It is difficult to link this data to the physical sense, and the influence of the different parameters (position and power) is in the same order of magnitude. So, the optimization results do not necessarily have a physical meaning but allow to obtain a correct temperature field. This shows the relevance of the equivalent conductivity method with optimization but it raises questions about its application on geometries with random wire layouts.

\subsection{Comparison of the temperatures for each equivalent conductivity}

Table 4 presents all attempts, and comparisons of the nodal model with the different thermal conductivities seen previously. The conductivity deduced from FLUENT is also solved with the nodal model. These optimized nodal results are nearest to FLUENT results and give a reference of ten values of thermal conductivity. The cumulative relative gap between FLuENT and optimization is 6.0 and $0.99^{\circ} \mathrm{C}$. The equivalent models $\mathrm{H} \& \mathrm{~S}$ and $\mathrm{M} \& \mathrm{~T}$ Models give two different results where the best cumulative gap is $6.6^{\circ} \mathrm{C}$ using the $\mathrm{M} \& \mathrm{~T}$ model against $37.5^{\circ} \mathrm{C}$ with the H\&S model. Furthermore, the M\&T model is closer to the thermal conductivity obtained by optimization on one value. The optimized thermal conductivity is $0.0691 \mathrm{~W} \cdot \mathrm{m}^{-1} \cdot \mathrm{K}^{-1}$, and the M\&T thermal conductivity is $0.0654 \mathrm{~W} \cdot \mathrm{m}^{-1} \cdot \mathrm{K}^{-1}$.

Therefore, these values do not use the same nodal model. The thermal conductivity of the M\&T model contains insulation conductivity, and the resistance of insulation used by Hellström is deleted. The thermal conductivity of optimization keeps this notion. So, these two values are not directly comparable. To confirm the value from the M\&T model, an optimization for one value was carried out using the nodal method without the insulation resistances. The new optimized conductivity is equal to $0.0659 \mathrm{~W} \cdot \mathrm{m}^{-1} \cdot \mathrm{K}^{-1}$ and this result confirms the pertinence of this model.

The information from Figure 10 completes the Table 4 and shows the gaps between each nodal model and FLUENT results. We can isolate the more precise model like M\&T. The first nodal model and M\&S Model always protect the wires from overheating, but they are less precise.

\section{Conclusion and overview}

This study applies and computes ILS models to solve a multi-source problem composed of multiple infinite cylinders in a conductive domain. We applied it to the electrical harness and enhanced it by easing the determination of the individual value of the thermal resistances (see section 2.3).

This method has been tested using a simple case with two wires to check the thermal behavior. The conclusion with the nodal model used in section 3 is the level of temperature at each core is respected against FLUENT 


\begin{tabular}{|c|c|c|c|c|c|c|c|c|c|c|c|c|}
\hline & $\lambda$ & $T_{1}$ & $T_{2}$ & $T_{3}$ & $T_{4}$ & $T_{5}$ & $T_{6}$ & $T_{7}$ & $T_{8}$ & $T_{9}$ & $T_{10}$ & $\begin{array}{c}\text { Cumulative } \\
\text { gap with FLuENT }\end{array}$ \\
\hline & $\frac{\mathrm{W}}{\mathrm{m} \cdot \mathrm{K}}$ & ${ }^{\circ} \mathrm{C}$ & ${ }^{\circ} \mathrm{C}$ & ${ }^{\circ} \mathrm{C}$ & ${ }^{\circ} \mathrm{C}$ & ${ }^{\circ} \mathrm{C}$ & ${ }^{\circ} \mathrm{C}$ & ${ }^{\circ} \mathrm{C}$ & ${ }^{\circ} \mathrm{C}$ & ${ }^{\circ} \mathrm{C}$ & ${ }^{\circ} \mathrm{C}$ & ${ }^{\circ} \mathrm{C}$ \\
\hline Fluent & / & 56.2 & 58.2 & 55.5 & 53.3 & 53.6 & 54.0 & 54.4 & 55.5 & 52.6 & 52.0 & 0 \\
\hline Nodal & 0.025 & 66.9 & 73.1 & 65.0 & 56.0 & 56.0 & 60.7 & 60.7 & 65.0 & 59.5 & 53.4 & 70.9 \\
\hline \multicolumn{13}{|c|}{ Model of equivalent $\lambda$} \\
\hline HESS Model & 0.0352 & 61.7 & 65.7 & 60.7 & 54.3 & 54.2 & 57.6 & 57.6 & 60.7 & 56.8 & 52.4 & 37.5 \\
\hline MEST Model & 0.0654 & 56.3 & 58.5 & 55.7 & 52.3 & 52.3 & 54.1 & 54.1 & 55.7 & 53.6 & 51.3 & 6.6 \\
\hline \multicolumn{13}{|c|}{ Optimization } \\
\hline$\lambda_{o p t}$ & 0.0691 & 56.4 & 59.0 & 55.4 & 52.2 & 52.2 & 53.9 & 53.9 & 55.4 & 53.4 & 51.2 & 6.0 \\
\hline$\lambda_{i, o p t}$ & $\begin{array}{l}0.025- \\
0.1998\end{array}$ & 56.4 & 58.2 & 55.5 & 53.4 & 53.6 & 54.0 & 54.4 & 55.5 & 52.6 & 51.6 & 0.99 \\
\hline
\end{tabular}

Table 4: Results from different applications of thermal conductivity in the nodal model. Input data from Figure 6 and Table 3 with the radius of limit at $4.2 \mathrm{~mm}$. It is compared with FLUENT results using the sum of square deviation of temperature

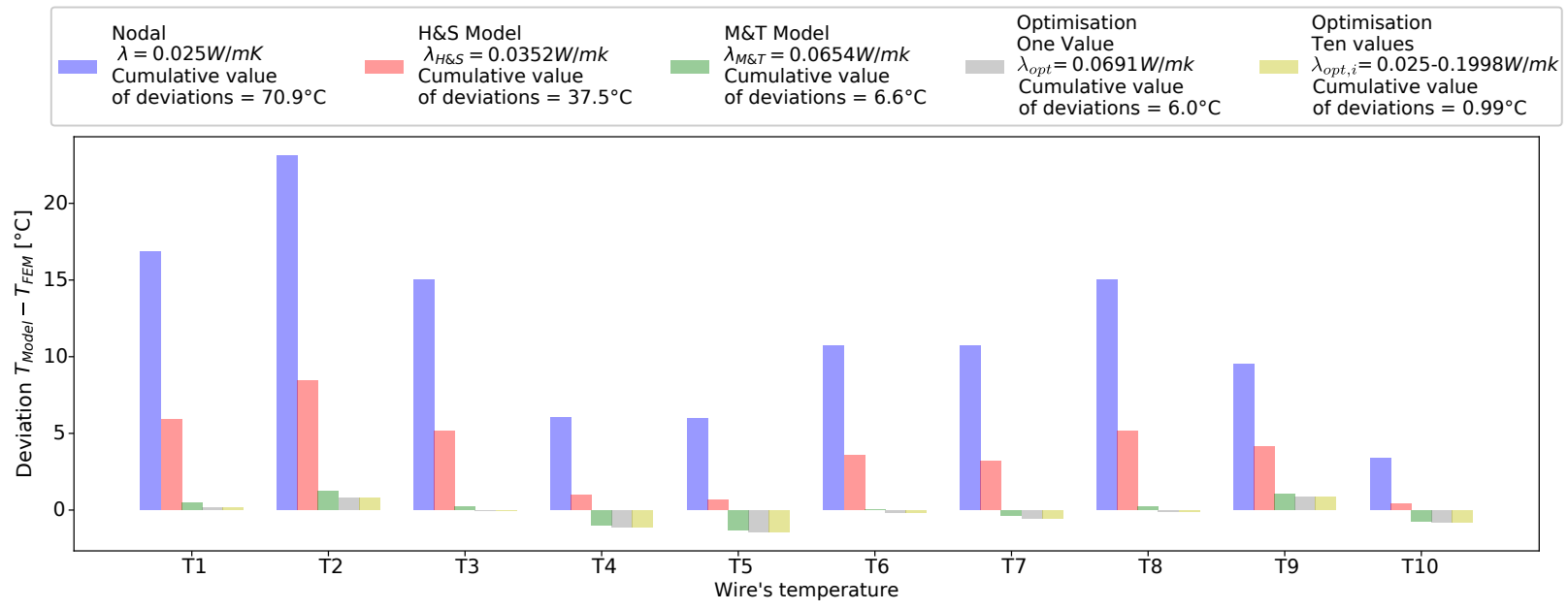

Figure 10: Deviation of values between each model and FLuent results

when the different sources are not in contact. The proximity between the two sources creates problems. The fluxes are modified by these domains when it is close to itself. It is not negligible. The gap grows bigger when the heat source is high and close to each other. However, each temperature found using the nodal method is higher than the results from FLUENT. It is a protective situation to design a harness.

The wires are often in a compacted disposition, and for this reason, the gap is corrected to make the model more precise. In section 4, a method based on equivalent thermal conductivity is developed to correct the problem. This section presents methods to find and to compare different conductivities. The results from FluENT have found the best way to correct the error gap. The M\&T model, which takes the three domains into account, gives the best results. The cumulative relative gap is $6.6^{\circ} \mathrm{C}$, while the higher relative gap for one 
wire is $1.3^{\circ} \mathrm{C}$. This last result is close to the best result found by the fitting. The results from fitting just one value of thermal conductivity give a criterion at $6.0^{\circ} \mathrm{C}$ against $6.6^{\circ} \mathrm{C}$ for the $\mathrm{M} \& \mathrm{~T}$ Model. Therefore, the closest protective model is $\mathrm{H} \& \mathrm{~S}$ Model. With the criteria at $37.5^{\circ} \mathrm{C}$, its precision is not optimal. The higher the power, the larger the deviation.

This study needs to be confirmed and improved. To do it, the results will be confirmed using different geometries and dispositions. Therefore, this study confirms a nodal network in simple geometries. This network represents internal thermal transfer in bundles with a fast and slight model. From this nodal network, it could be easy to replace the Dirichlet condition by a Robin condition to adapt the model to each different situation. So this network can be adapted according to the needs identified in different areas like automobile industry, aeronautics. With different adaptations to represent the harness environment, it will be possible to quickly solve a lot of configurations to provide answer to designers for more and more complex electrical architecture in a vehicle. Different ways of adding the notion of radiation which could exist between adjoining wires are currently being studied and could be added to this nodal network. The approach described allows to quickly assess harness geometries to identify the best and worst cases, and thus helps to design harnesses.

\section{Aknowledgement}

The authors express their gratitude to the Groupe PSA, to the EIPHI University Research School (contract "ANR-17-EURE-0002") and to the National Association for Research and Technology (ANRT convention "2017/1091") for their support in carrying out this work.

[1] P. Parsania, K. Saradava, Drive-By-Wire Systems In Automobiles, in: Journal of systematic computing : VVP Engineering, Vol. 6, 2012.

[2] G. Leen, D. Heffernan, Expanding automotive electronic systems, Computer 35 (1) (2002) 88-93. doi: $10.1109 / 2.976923$.

[3] B. Agard, Contribution to a product design methodology in a context of wide diversity, Theses, Institut National Polytechnique de Grenoble - INPG (Jul. 2002).

[4] E. Aguirre, B. Raucent, Economic comparison of wire harness assembly systems, Journal of Manufacturing Systems 13 (4) (1994) 276-288. doi:10.1016/0278-6125(94)90035-3.

[5] J. Brito Filho, Heat transfer in bare and insulated electrical wires with linear temperature-dependent resistivity, Applied Thermal Engineering 112 (Supplement C) (2017) 881-887. doi:10.1016/j. applthermaleng.2016.10.172.

[6] R. de Lieto Vollaro, L. Fontana, A. Vallati, Experimental study of thermal field deriving from an underground electrical power cable buried in non-homogeneous soils, Applied Thermal Engineering 62 (2) (2014) 390-397. doi:10.1016/j.applthermaleng.2013.09.002.

[7] C. Hwang, Y. Jiang, Extensions to the finite element method for thermal analysis of underground cable systems, Electric Power Systems Research 64 (2) (2003) 159-164. doi:10.1016/S0378-7796(02)00192-X.

[8] H. Carslaw, J. Jaeger, Conduction of Heat in Solids, OXFORD UNIV PR, 1959. 
[9] J. Grandvuillemin, D. Chamagne, R. Glises, C. Tiraby, F. Degrange, Thermal Modelling Of Enclosed Cables

[21] S. Morchio, M. Fossa, Thermal modeling of deep borehole heat exchangers for geothermal applications in densely populated urban areas, Thermal Science and Engineering Progress 13 (2019) 100363. doi: $10.1016 / j \cdot$ tsep.2019.100363. 
[22] R. Mignot, R. Glises, C. Espanet, E. Saint Ellier, F. Dubas, D. Chamagne, Design of an axial flux PM motor using magnetic and thermal equivalent network, The European Physical Journal Applied Physics 63 (3) (2013) 30901. doi:10.1051/epjap/2013120522.

[23] G. Guemo, G. Romuald, Thermal modelling of permanent magnet synchronous machine, Theses, INSA de Lyon (Feb. 2014).

[24] E. Heymsfield, J. W. Daniels, R. F. Saunders, M. L. Kuss, Developing anti-icing airfield runways using surface embedded heat wires and renewable energy, Sustainable Cities and Society 52 (2020) 101712. doi: $10.1016 / j . s c s .2019 .101712$.

[25] J. W. Daniels, E. Heymsfield, R. F. Saunders, M. L. Kuss, Development of automated electrical heat grid for pavement snowmelt, Thermal Science and Engineering Progress 10 (2019) 169 - 178. doi:10.1016/j. tsep.2019.01.004.

[26] Y. Nian, W. Cheng, Analytical g-function for vertical geothermal boreholes with effect of borehole heat capacity, Applied Thermal Engineering 140 (2018) 733-744. doi:10.1016/j.applthermaleng.2018.05. 086.

[27] F. Incropera, T. Bergman, D. DeWitt, A. Lavine, Fundamentals of Heat and Mass Transfer, Wiley, 2013.

[28] R. R. McMurchy, R. G. Payne, R. L. Dotts, Thermal Network Modelling Handbook, techreport NASA-CR144418, TRW-14690-H003-RO-00, NASA United States (Jan. 1972). URL https://ntrs.nasa.gov/search.jsp?R=19750022410

[29] I. Naveros, C. Ghiaus, J. Ordoñez, D. P. Ruiz, Thermal networks considering graph theory and thermodynamics, in: J. P. Meyer (Ed.), HEFAT2016 : 12th International Conference on Heat Transfer, Fluid Mechanics and Thermodynamics, EDAS, Costa del Sol, Spain, 2016, pp. 1568-1573.

URL http://150.214.203.12/differential/wp-content/uploads/2017/09/Naveros_Thermal_2016. pdf

[30] J. Petitgirard, P. Baucour, D. Chamagne, E. Fouillien, Multi-source thermal model for electrical harness design, Vol. ASME 2019 Heat Transfer Summer Conference of Summer Heat Transfer Conference, 2019. doi:10.1115/HT2019-3516.

[31] P. S. R. Murthy, Power Systems Analysis (Second Edition), second edition Edition, ButterworthHeinemann, Boston, USA, 2017, Ch. 2 - Graph Theory, 3 - Incidence Matrix, pp. 6-52. doi:10.1016/ B978-0-08-101111-9.00002-1. URL http://www.sciencedirect.com/science/article/pii/B9780081011119000021

[32] C. Geuzaine, J.-F. Remacle, Gmsh: A 3-D finite element mesh generator with built-in pre- and postprocessing facilities, International Journal for Numerical Methods in Engineering 79 (11) (2009) 1309-1331. doi:10.1002/nme. 2579 .

[33] T. Mori, K. Tanaka, Average stress in matrix and average elastic energy of materials with misfitting inclusions, Acta Metallurgica 21 (5) (1973) 571-574. doi:10.1016/0001-6160(73)90064-3. 
[34] W. Perrins, D. McKenzie, R. McPhedran, Transport properties of regular arrays of cylinders, Proceedings of the Royal Society of London A: Mathematical, Physical and Engineering Sciences 369 (1737) (1979) 207-225. doi:10.1098/rspa.1979.0160.

[35] Z. Hashin, S. Shtrikman, A variational approach to the theory of the elastic behaviour of multiphase materials, Journal of the Mechanics and Physics of Solids 11 (2) (1963) 127-140. doi:10.1016/0022-5096(63) 90060-7.

[36] W. Voigt, Ueber die Beziehung zwischen den beiden Elasticitätsconstanten isotroper Körper, Annalen der Physik 274 (12) (1889) 573-587. doi:10.1002/andp.18892741206.

[37] A. Reuss, Berechnung der Fließgrenze von Mischkristallen auf Grund der Plastizitätsbedingung für Einkristalle ., ZAMM - Journal of Applied Mathematics and Mechanics / Zeitschrift für Angewandte Mathematik und Mechanik 9 (1) (1929) 49-58. doi:10.1002/zamm.19290090104.

[38] G. Milton, Bounds on the transport and optical properties of a two-component composite material, Journal of Applied Physics 52 (8) (1981) 5294-5304. doi:10.1063/1.329386.

[39] S. Torquato, F. Lado, Bounds on the Effective Transport and Elastic Properties of a Random Array of Cylindrical Fibers in a Matrix, Journal of Applied Mechanics 55 (2) (1988) 347-354. doi:10.1115/1. 3173681.

[40] C. Kelley, Iterative Methods for Optimization, Frontiers in Applied Mathematics, Society for Industrial and Applied Mathematics, 1999. doi:10.1137/1.9781611970920.

[41] M. Branch, T. Coleman, Y. Li, A Subspace, Interior, and Conjugate Gradient Method for Large-Scale Bound-Constrained Minimization Problems, SIAM Journal on Scientific Computing 21 (1) (1999) 1-23. doi:10.1137/S1064827595289108. 